ORIGINAL ARTICLE

\title{
Nasal Cavity and Paranasal Sinuses Metastasis
}

\author{
Carlos S Ruggeri ${ }^{1 *}$, Lautaro Acosta ${ }^{2}$, Valentina Proietti ${ }^{2}$ and Candelaria Serrano ${ }^{3}$
}

${ }^{1}$ Chief of the Rhinosinusology Section, Department of the Otorhinolaryngology, Hospital Italiano of Buenos Aires, Argentina ${ }^{2}$ Resident, Otorhinolaryngology Department, Hospital Italiano of Buenos Aires, Argentina

*Corresponding author: Carlos S Ruggeri, Chief of the Rhinosinusology Section, Department of Otorhinolaryngology, Hospital Italiano of Buenos Aires, Perón 4190, Ciudad Autónoma de Buenos Aires, Argentina

\begin{abstract}
Introduction: Metastasis in the nasal cavity and paranasal sinuses are rare. The most common tumor that produces them is clear cell renal carcinoma. The objective of the study is to determine the incidence of metastases in the nasal cavity and paranasal sinuses among malignant rhinosinusal tumors in our patient poblation and survival after rhinosinusal metastasis treatment.

Methods: The medical records of all patients who had malignant rhinosinusal tumors diagnosed and treated in the hospital Italiano of Buenos Aires from 1989 to 2019 were
\end{abstract} retrospectively reviewed.

Patients who had metastases of primary neoplasms located outside the head were selected.

Results: 67 patients with malignant tumors located in the nasal cavity and paranasal sinuses were diagnosed and treated.

Eight patients had metastases in the nasal cavity and paranasal sinuses.

All the patients at the time the metastasis was diagnosed had a controlled primary neoplasm. The treatments indicated were: Endonasal surgery with endoscopes with complete resection of the metastasis (3/8), radiotherapy (4/8), and chemo/radiotherapy $(1 / 8)$.

Only two patients who died from systemic metastases had persistent tumor in the paranasal sinuses (25\%).

Survival at one and two years was $75 \%$ and $25 \%$ respectively.

Conclusions: The incidence of metastasis in the nasal cavity and paranasal sinuses among malignant neoplasms of the rhinosinusal region was $11.94 \%$.

Survival was poor, but the performed treatments had a high rate of local control and improved the quality of life of the patients.

\author{
Keywords \\ Metástasis, Nasal cavity, Paranasal sinuses, Endoscopic \\ surgery
}

\section{Introduction}

Metastases in the nasal cavity and paranasal sinuses are rare [1].

Several primary neoplasms of different organs can metastasize in the rhinosinusal region, the most common being those produced by clear cell renal cell adenocarcinoma [2].

Treatments are different and must be individualized according to the histological characteristics, location and extent of metastases, control of the primary tumor, coexistence of other metastases, and the patient's wishes.

Treatment of metastasis is aimed at improving survival and quality of life for patients.

The objective of the study is to determine the incidence of metastases in the nasal cavity and paranasal sinuses among malignant rhinosinusal tumors in our population and survival after treatment of rhinosinusal metastasis.

\section{Methods}

The medical records of patients who had malignant rhinosinus tumors, diagnosed and treated at the Italian hospital in Buenos Aires between 2003 and 2019, were reviewed.

The patients who were diagnosed and treated for 
Table 1: Patients treated with metastases in the nasal cavity and paranasal sinuses.

\begin{tabular}{|c|c|c|c|c|c|c|}
\hline Sex/age & Primary tumor & Histology & Metastasis & Signs/symptoms & Treatment & Survival \\
\hline Male: 52 & Kidney & $\begin{array}{l}\text { Clear cell } \\
\text { adenocarcinoma }\end{array}$ & Maxillary sinus & $\begin{array}{l}\text { Nasal obstruction } \\
\text { epistaxis }\end{array}$ & $\begin{array}{l}\text { Radiotheraphy } \\
+ \text { quimiotherapy }\end{array}$ & 12 months \\
\hline Female: 42 & Endometrium & Adenocarcinoma & Frontal sinus & Tumor & Radiotheraphy & 7 months \\
\hline Female: 49 & Cervix & $\begin{array}{l}\text { Squamous cell } \\
\text { carcinoma }\end{array}$ & $\begin{array}{l}\text { Sphenoid sinus/ } \\
\text { clivus }\end{array}$ & Dysphonia/dysglusia & Radiotheraphy & 16 months \\
\hline Male: 61 & Liver & Hepatocarcinoma & Maxillary sinus & Nasal obstruction & Radiotheraphy & 12 months \\
\hline Male: 62 & Kidney & $\begin{array}{l}\text { Clear cell } \\
\text { adenocarcinoma }\end{array}$ & Nasal septum & Epistaxis & $\begin{array}{l}\text { Endoscopic } \\
\text { surgery }\end{array}$ & 30 months \\
\hline Male: 5 & Abdomen & Neuroblastoma & Sphenoid sinus & Hallazgo RMN & $\begin{array}{l}\text { Endoscopic } \\
\text { surgery }\end{array}$ & 4 months \\
\hline Male: 65 & Kidney & $\begin{array}{l}\text { Clear cell } \\
\text { adenocarcinoma }\end{array}$ & $\begin{array}{l}\text { Maxillary sinus/ } \\
\text { ethmoid }\end{array}$ & $\begin{array}{l}\text { Nasal obstruction } \\
\text { epistaxis }\end{array}$ & $\begin{array}{l}\text { Radiotheraphy + } \\
\text { quimiotherapy }\end{array}$ & 48 months \\
\hline Male: 62 & Kidney & $\begin{array}{l}\text { Clear cell } \\
\text { adenocarcinoma }\end{array}$ & Lower turbinate & $\begin{array}{l}\text { Nasal obstruction } \\
\text { epistaxis }\end{array}$ & $\begin{array}{l}\text { Endoscopic } \\
\text { surgery }\end{array}$ & 12 months \\
\hline
\end{tabular}

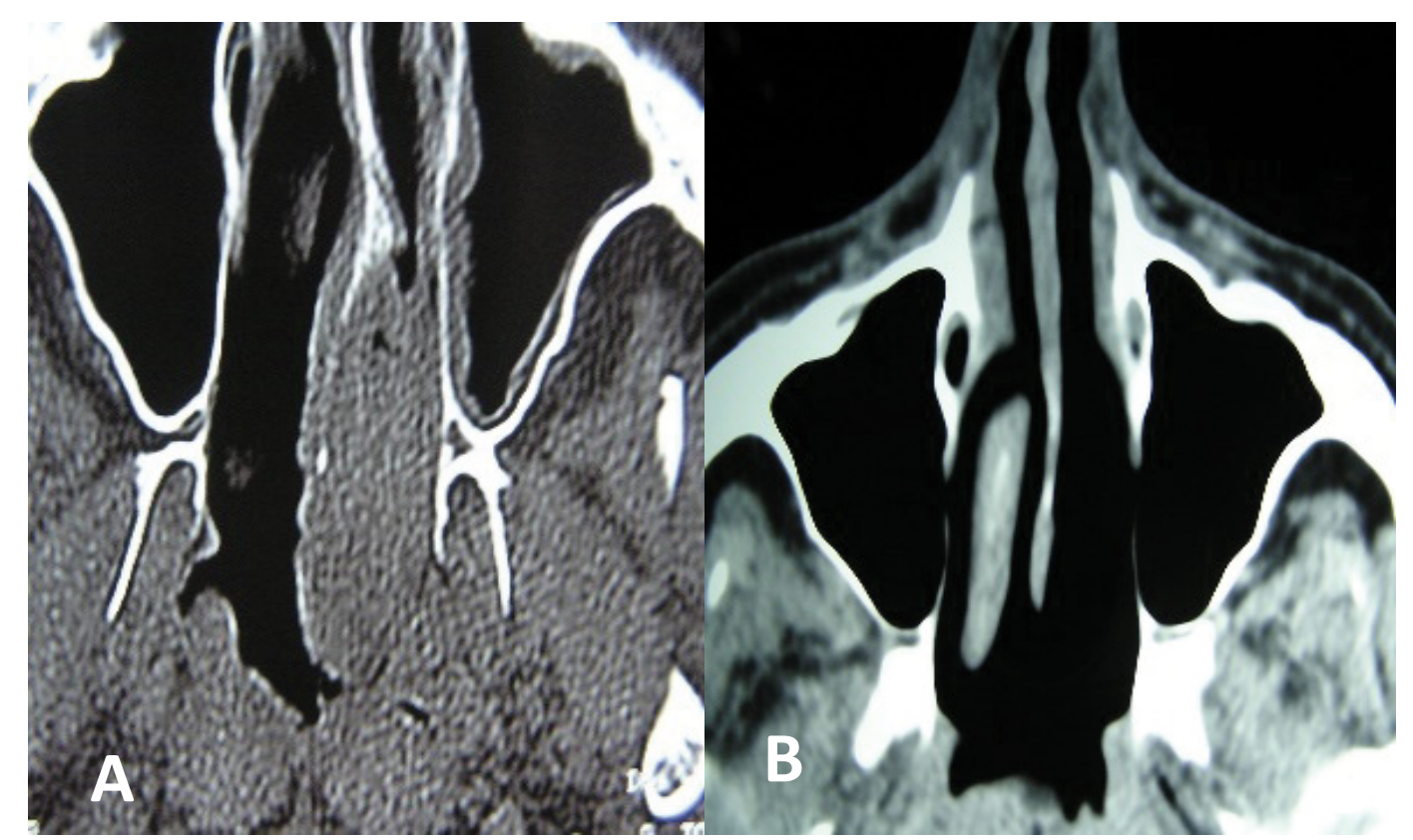

Figure 1: Metastasis of clear cell renal adenocarcinoma in the posterior third of the nasal septum. Endonasal resection with endoscopes (A) Pre and (B) Postoperative.

having metastases of primary neoplasms located outside the head were selected.

The following data were collected in an Excel table: Sex and age of the patient, consultation sign/symptom, location of metastasis, type of primary neoplasia, treatment, and survival (Table 1).

The patients were evaluated by nasal endoscopy and different imaging studies: Tomography of the face and neck, brain, thorax, abdomen and pelvis, magnetic resonance imaging, bone scintigraphy, and positron emission tomography.

The indicated treatments varied according to the location, extent and histology of the metastasis, the status of the primary tumor (controlled or untreated), and the patient's desire.
A biopsy was performed in all of them to confirm the histological type of metastasis, in seven it was done through the endonasal route and in one by a bicoronal approach to access the frontal sinus.

In two patients with kidney adenocarcinomas an intraoperative biopsy was performed under general anesthesia by endonasal approachwhich confirmed the diagnosis of a malignant tumor and then a complete excision of the tumor in the posterior third of the nasal septum and in another of the inferior turbinate was performed by the same approach.

It was confirmed that the resection was complete by the intraoperative histological study of the surgical margins (Figure 1 and Figure 2).

In a 5-year-old boy an endonasal approach was 


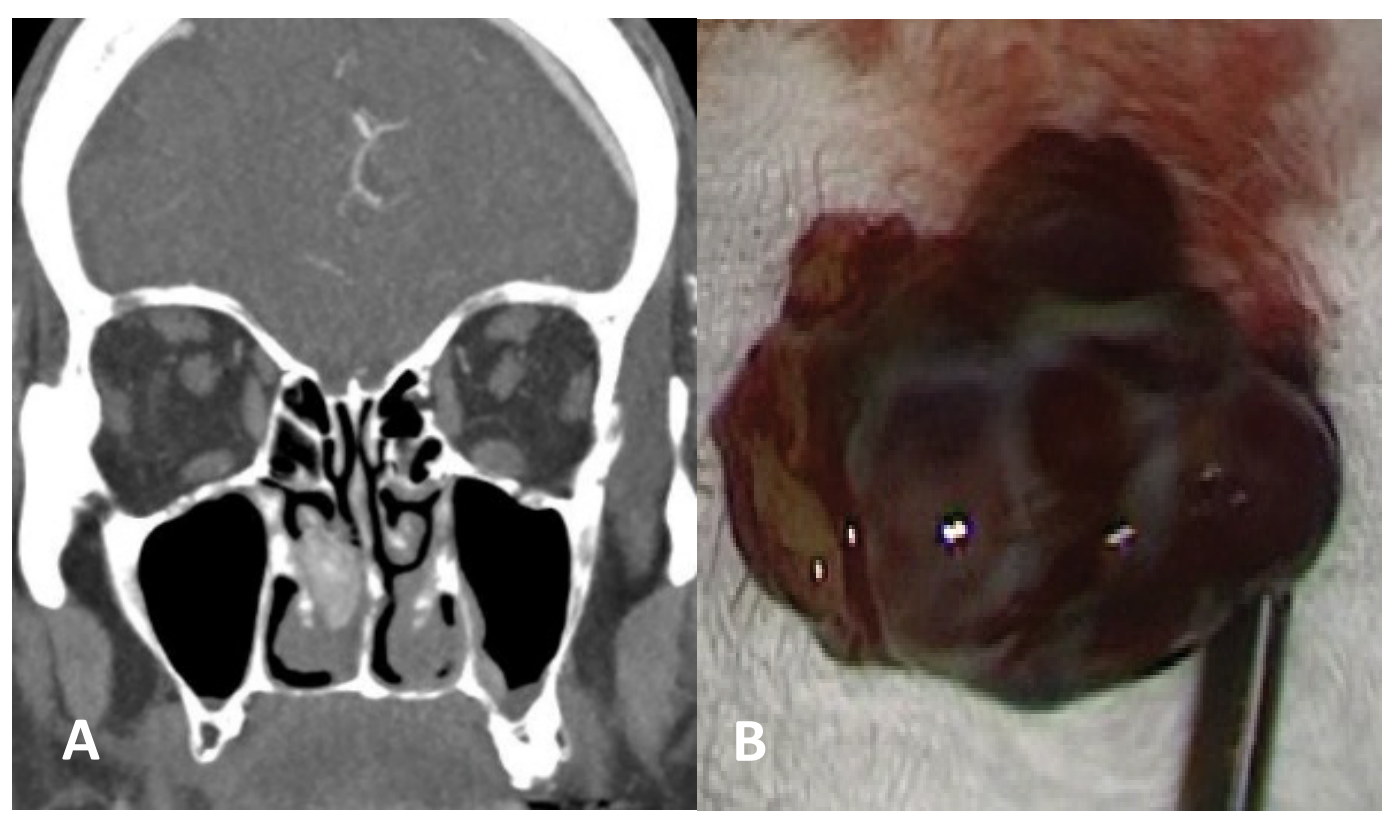

Figure 2: Clear cell renal adenocarcinoma metastasis in the inferior turbinate. Endonasal resection with endoscopes: (A) Tomography and; (B) Surgical specimen.

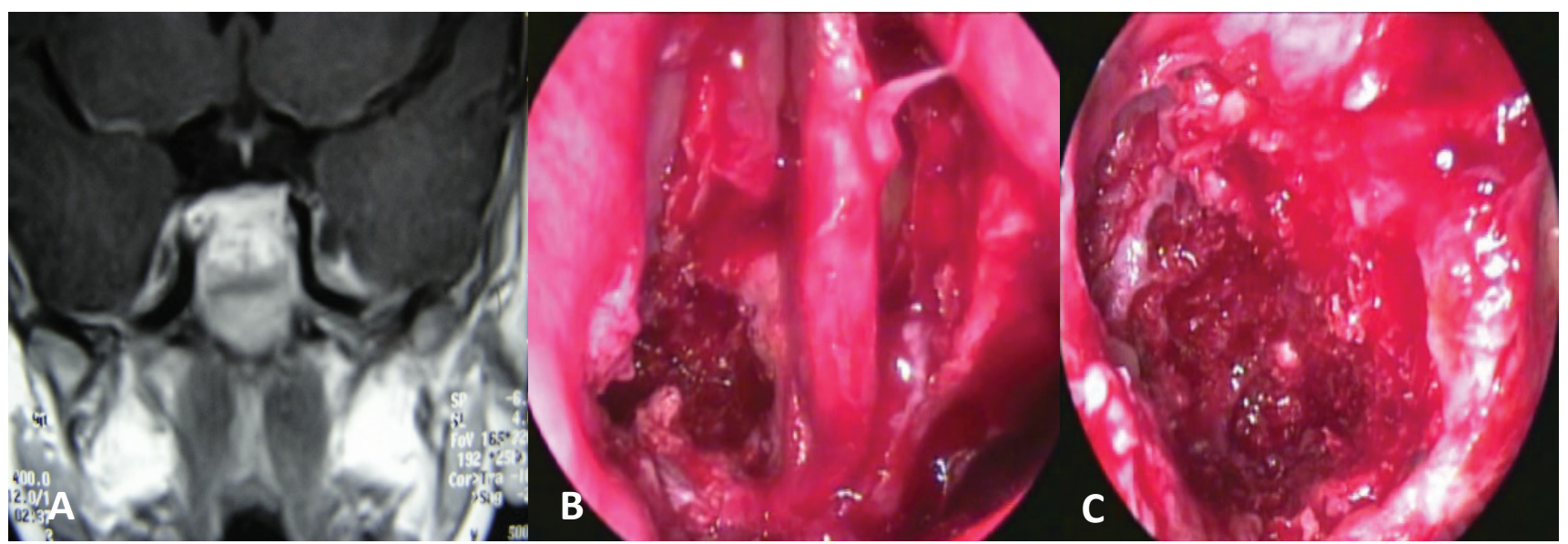

Figure 3: Sphenoid abdominal neuroblastoma metastasis. Transnasal resection with endoscopes: (A) MRI; (B,C) Bilateral sphenoidotomy and tumor resection.

made to the sphenoid sinus with endoscopes and a single metastasis from an abdominal neuroblastoma was resected (Figure 3).

The radiotherapy technique that was indicated was conventional in 3 conformational $3 \mathrm{D}$ in one and in the other intensity modulate.

The control of the patients was made in conjunction with the oncologist and images and nasal endoscopy were used.

\section{Results}

Sixty-seven patients with malignant tumors located in the nasal cavity and paranasal sinuses were diagnosed and treated.

Eight patients had metastases in the nasal cavity and paranasal sinuses.

The incidence of metastases in the nasal cavity and paranasal sinuses within the group of malignant neoplasms in the region was $11.94 \%$.

Six were men and two were women, the youngest was 5 and the oldest 65-years-old (average age: (49.75).

In six patients the metastases were located in the paranasal sinuses (maxilla: $2 / 6$, sphenoid: $2 / 6$, frontal: $1 / 6$ and ethmoid: $1 / 6$ ), and in two in the nasal cavity (posterior sector of the nasal septum and in the inferior turbinate).

The primary malignant tumors that originated the metastases were located in the kidney (4/8) and corresponded to a clear cell adenocarcinoma, cervix and endometrium (2/8), with histology of squamous cell carcinoma and adenocarcinoma. One patient had a metastasis from an abdominal neuroblastoma, and another from a hepatocarcinoma.

All patients at the time the metastasis was diagno- 
sed had controlled primary neoplasia.

The average time of appearance was 20 months after treatment of the tumor of origin.

In six patients the metastases had a single location in the nasal cavity and paranasal sinuses and in another two they coexisted with lesions in the lung and neck and in another in the abdomen.

The signs and symptoms that originated the consultation were: Nasal obstruction and epistaxis $(4 / 8$, all due to clear cell renal adenocarcinoma), unilateral nasal obstruction (1/8), frontal tumor (1/8), dysphonia and dysglusia (1/8) and imaging finding (1/8).

The treatments indicated were: Endonasal surgery with endoscopes with complete resection of the metastasis (3/8), radiotherapy (4/8: In two because they did not accept a radical maxillectomy), and chemo/radiotherapy (1/8).

Three patients with metastatic clear cell renal cell carcinoma received adjuvant sunitinib (a tyrosine kinase inhibitor with antitumor and anti angiogenic effect).

The mean follow-up time was 18 months.

Four patients died of disseminated disease: 4, 7, 30 and 48 months after treatment. Three patients did not have local or systemic disease during 1 year of follow-up. Two of them did not return to control.

In the patient who had a complete resolution of the solitary metastasis in the sphenoid and clivus due to an epidermoid carcinoma of the cervix, another bone metastasis in the spine was diagnosed four months later. She was successfully treated with surgery and radiation therapy and no disease was detected for 1 year.

Only two patients who died from systemic metastases had persistence of the tumor in the paranasal sinuses (25\%).

Survival at one and two years was $75 \%$ and $25 \%$.

\section{Discussion}

Metastases located in the nasal cavity and paranasal sinuses are uncommon [1], representing 0.21 to $2.1 \%$ of all oral and maxillofacial tumors [2].

Lund [3] reported 10 metastases in the nasal cavity and paranasal sinuses among 1,635 rhinosinusal malignancies. Three metastases were from cutaneous melanomas located on the back and lower limb, three from pancreatic neoplasms, two from the prostate, one from the ovary and one from the kidney.

In our study we had 8 patients with rhinosinusal metastases among 67 rhinosinusal malignancies (11.94\%), an incidence higher than that reported in the literature.

Different malignant neoplasms originating in any organ can metastasize in the rhinosinusal region. Clear cell renal cell carcinoma is the most common, accoun- ting for $50 \%$ of metastases in the region. It is considered that $10 \%$ of patients with clear cell renal cell carcinoma could present with head and neck metastases [4].

Other origins described are: Breast, colon, prostate, thyroid, uterus, ovary, etc [5].

In our study, kidney adenocarcinoma metastases predominated (4/8: $50 \%$ ).

The most common locations of metastases are the maxillary sinus, followed by the sphenoid, ethmoid, frontal sinus and nasal cavity [5].

In our study, the distribution of the location of metastases was similar.

Metastases can occur hematogenously or lymphatically.

The paraspinal venous plexus (Batson's plexus) is a valveless, low-pressure system that communicates with the deep veins of the pelvis, intercostal veins, vena cava, and the azygos system. Any increase in intra-abdominal pressure can produce retrograde venous outflow and allow tumor cells to reach the head and neck region.

Another theory explains that the solitary metastasis would be produced by the existence of communications between the right and left heart. In this way, the neoplastic cells would reach the right atrium through the inferior vena cava, pass through the interatrial communication to the left atrium, and from there via the arterial route they would reach the pterygoid plexus or the cavernous sinus and would implant in the paranasal sinuses.

Neoplastic cells could also previously cross the lung, leaving micrometastases that cannot be diagnosed with plain radiography or chest tomography, or lung metastases from kidney cancer could regress due to immunological reactions in 1 to $5 \%$ of cases before implantation in nasal cavity or paranasal sinuses $[5,6]$.

Extension via the lymphatic route would be less common, it would occur because the neoplastic emboli would pass from the regional lymph nodes to the thoracic duct and through a retrograde flow would reach the head and neck region through the intercostal, mediastinal, or supraclavicular lymphatic vessels [5].

The signs and symptoms of rhinosinusal metastases are similar to those of other malignant neoplasms in the region.

Clear cell renal cell adenocarcinoma and hepatocarcinoma metastases are highly vascular, so the presence of epistaxis is common $[5,7]$.

In our study, the four patients with renal adenocarcinoma metastasis had epistaxis as the initial reason for consultation, and unilateral nasal obstruction was added in two.

It is important to consider the high vascularity of 
these lesions, and to perform biopsies preferably under general anesthesia and in the operating room.

The prognosis of metastases in the nasal cavity and paranasal sinuses is not good, and they can alter the quality of life of the patient, causing epistaxis, severe facial pain and nasal obstruction.

Palliative treatment with radiation therapy and/or chemotherapy can take place in selected patients with poor quality of life.

Patients with metachronous metastases who have a controlled primary tumor may benefit from surgical excision of the metastasis [8], even if the resection involves a craniofacial approach [9].

Endonasal surgery with endoscopes may be the best oncological surgical technique to resect localized lesions in the nasal cavity or in the paranasal sinuses with minimal morbidity in selected patients.

In one study, they recommended performing digital angiography with embolization to reduce bleeding that can be caused by biopsy or cancer resection [10].

In our series, we treated three patients with endonasal surgery with endoscopes, with the intention of performing a complete resection.

In the two patients with renal carcinoma metastases, complete endonasal excision was performed without having indicated a previous embolization and we did not have bleeding that made surgery difficult.

The three operated patients had no local persistence, but two of them died at 4 and 30 months due to disseminated disease.

Two other patients (renal carcinoma and hepatocarcinoma) did not accept radical maxillectomy and were treated with radiotherapy. They were evaluated for one year without showing recurrences, and did not return to control.

In renal carcinoma metastases treated by surgery after nephrectomy, they reported a 2-year survival of $41 \%$, and a 5 -year survival of $13 \%[11,12]$.

In other studies, they reported good results with radiation treatment in renal cancer metastasis $[12,13]$.

DiBiase reported an $86 \%$ palliative response with a $49 \%$ complete response to radiotherapy treatment in renal carcinoma metastases [14].

Radiotherapy after complete surgical excision of rhinosinusal metastases from kidney cancer would have no impact on survival $[12,13]$.

In cases of systemic metastases from renal cancer, concomitant to rhinosinusal lesions, systemic therapy with different medications may be indicated: Interferon alpha, interleukin 2 , sunitinib, temsirolimus, and antiangiogenic therapy $[13,15]$.
In a series of 10 patients with metastases from different neoplasms in the nasal cavity and paranasal sinuses, Lund [3] reported a poor prognosis, all patients died within a few months after diagnosis.

In metastases from breast, stomach, and bladder tumors, survival after diagnosis was 1 to 2 months, and in metastases from primary kidney, bronchus, or adrenal gland tumors, survival was 24 months or more.

A review of the few published cases of rhinosinusal metastases from hepatocarcinoma reported an average survival of 8.9 months [16].

In our study, survival was poor: $75 \%$ at 1 year and $25 \%$ with a 2-year follow-up. Only two patients who died had persistent rhinosinusal metastasis.

\section{Conclusions}

The incidence of metastases in the nasal cavity and paranasal sinuses among malignant neoplasms in the rhinosinusal region was $11.94 \%$.

Survival was poor, but the treatments carried out enabled a high rate of local control and improved the quality of life of the patients.

Endonasal surgery with endoscopes in selected patients allowed oncological resections with little morbidity.

\section{Authors Declaration}

We have no conflicts of interest.

There was no financing.

\section{References}

1. Barnes $L$ (2009) Metastases to the head and neck: an overview. Head Neck Pathol 3: 217-224.

2. Mo-Lun Shen, Jian Kang, Yan-Li Wen, Wei-Min Ying, Jie Yi, et al. (2009) Metastatic tumors to the oral and maxillofacial region: A retrospective study of 19 cases in West China and review of the Chinese and English literature. $\mathrm{J}$ Oral Maxillofac Surg 67: 718-737.

3. Lund V, Howard D, Wei W (2014) Metastases to the nasal cavity and paranasal sinuses, in Tumors of the Nose, Sinuses and Nasopharynx. Thieme Medical Publishers, Inc., 333 Seventh Avenue, New York, USA, 397-402.

4. Sung-Lyong Hong, Da-Woon Jung, Hwan-Jung Rob, KyuSup Cho (2013) Metastatic renal cell carcinoma of the posterior nasal septum as the first presntation 10 years after nephrectomy. J Oral Maxillofac Surg 71: 1813.e1-1813.e7.

5. López F, Devaney K, Hanna EY, Rinaldo A, Ferlito A (2016) Metastases to nasal cavity and paranasal sinuses. Head \& Neck 1-8.

6. Monserez D, Vlaminck S, Kuhweide R, Casselman J (2001) Symmetricalethmoidal metastases from ductal carcinoma of the breast, suggesting transcribrosal spread. Acta Otorhinolaryngol Belg 55: 251-257.

7. Pierre-Louis Bastier, Dorothée Dunion, Guillaume de Bonnecaze, Elie Serrano, Ludovic de Gabory (2018) Renal cell carcinoma metastatic to the sinonasal cavity: A review and report of 8 cases. ENT-Ear, Nose \& Throat Journal 97: E6-E12. 
8. Mahajan R, Mayappa N, Prashanth V (2015) Metastasic renal carcinoma presentingas nasal mass: case report and review of literature. Indian J Otolaryngol Head Neck Surg 68: 374-376.

9. Nason R, Carrau RL (2004) Metastatic renal cell carcinoma to the nasal cavity. Am J Otolaryngol 25: 54-57.

10. Pritchyk KM, Schiff BA, Newkirk KA, Krowiak E, Deeb ZE (2002) Metastatic renal cell carcinoma to the head and neck. Laryngoscope 112: 1598-1602.

11. Gottlieb MD, Roland JT (1998) Paradoxical spread of renal cell carcinoma to the head and neck. Laryngoscope 108: 238-241.

12. Simo R, Sykes AJ, Hargreaves SP, Axon PR, Birzgalis AR, et al. (2000) Metastatic renal cell carcinoma to the nose and paranasal sinuses. Head Neck 22: 722-727.
13. Ziari M, Shen S, Amato RJ, Teh BS (2006) Metastatic renal cell carcinoma to the nose and ethmoid sinus. Urology 67: 199.

14. DiBiase SJ, Valicenti RK, Schultz D, Xie Y, Gomella LG (1997) Palliative radiation for focally symptomatic renal cell carcinoma: Support for dose escalation based on biological model. J Urol 158: 746-749.

15. Choong CV, Tang T, Chay WY, Goh C, Tay MH, et al. (2011) Nasal metastases from renal cell carcinoma are associated with Memorial Sloam Kettering Cancer Center poor prognosis classification. Chin J Cancer 130: 144-148.

16. Hsieh CT, Sun JM, Tsai WC, Tsai TH, Chiang YH, et al. (2007) Skull metastasis from hepatocellular carcinoma. Acta Neurochir (Wien) 149: 185-190. 